\title{
O GRANDE TEATRO DO MUNDO: GLOBALIZACCÃO E COSMOPOLITISMO EM O DRAGÃO DOURADO, DE ROLAND SCHIMMELPFENNIG
}

ALL THE WORLD IN A STAGE: GLOBALIZATION AND COSMOPOLITANISM IN ROLAND SCHIMMELPFENNIG'S THE GOLDEN DRAGON

Vítor Nogueira Alves* Vinícius Paulo Corrêa Almeida* *vnogueiraalves@yahoo.com.br Mestrando em Letras pela Universidade Federal de São João del-Rei (UFSJ). Tem graduação em Letras pela UFSJ.

* viniciusmahier@hotmail.com

Doutorando em Estudos Literários pela Universidade Federal de Juiz de Fora (UFJF). Tem graduação e mestrado em Letras pela Universidade Federal de São João del-Rei (UFSJ). Graduando em Teatro também pela UFSJ.

RESUMO: Encenada pela primeira vez em 2009, a peça O Dragão Dourado [Der Goldene Drache], do dramaturgo alemão Roland Schimmelpfennig, gira em torno de um imigrante chinês na co. e à migração. Partindo do conceito goethiano cosmopolitisno è a migraço. Patindo do conceito goethiano de literatura mundial, propomos uma leitura da peça baseada, em grande parte, nas ideias de Homi Bhabha $(2003,2011)$ sobre os locais da cultura e sobre as diferenças entre cosmopolitismo global e vernacular. Procuramos desenredar algumas dificuldades da complexa peça de Schimmelpfennig a fim de mostra como o texto articula esses problemas.

PALAVRAS-CHAVE: Roland Schimmelpfennig; Globalização; Cosmopolitismo; Cosmopolitismo vernacular; Literatura alemã contemporânea.
ABSTRACT: Roland Schimmelpfennig's 2009 play The Golden Dragon [Der Goldene Drache] revolves around a Chinese immigrant working in the kitchen of an Asian restaurant in Europe. The central themes of the play are ones such as globalization, immigration, and cosmopolitani iterature concept and drawing from Homi Bhabha's $(2003,2011)$ insights on culture and on both vernacular and global cosmopolitanism, we attempt to untangle some of the many complexities of Schimmelpfennig's play in order to demonstrate how it approaches these themes.

KEYWORDS: Roland Schimmelpfennig; Globalization; Cosmopolitanism; Vernacular cosmopolitanism; Contemporary German literature. 


\section{INTRODUÇÃO}

"A litera tura nacional hoje já não significa grande coisa, é chegada a época de uma literatura mundial, e todos devem trabalhar no sentido de apressá-la" - isto, o trecho talvez soe familiar, foi J. W. von Goethe em uma de suas conversas registradas por Johann Peter Eckermann ([1836] 2017, p. 228). Nela, o poeta menciona seu conceito de literatura mundial [Weltliteratur] que, como registra Edward Said (2017, p. 21), refere-se ao "estudo do conjunto das literaturas do mundo visto como um todo sinfônico que podia ser apreendido teoricamente, preservando-se a individualidade de cada obra sem perder o todo de vista". Homi Bhabha (2003, p. 33), no entanto, questiona o quão "mundial" seria de fato a Weltliteratur, pois nela "as referências imediatas de Goethe são, naturalmente, as guerras napoleônicas, e seu conceito de 'sentimento de boa vizinhança' é profundamente eurocêntrico, chegando no máximo à Inglaterra e à França”. Mesmo assim, Bhabha (2003, p. 33) reconhece que "como orientalista que leu Shakuntala aos dezessete a nos e que escreve em sua biografia sobre o 'informe e desconforme' deus-macaco Ha numan, as especulações de Goethe estão abertas a outra linha de pensamento". Entre elas, podem-se contar as afinidades entre a Weltliteratur e os questiona mentos levantados pela globalização, já que a proposta goethia na tem sido revisitada desde o surgimento deles (APTER, 2013, p. 1-2).
São várias as obras literá rias ligadas a essas questões, mas pretendemos discutir especificamente a peça O Dragão Dourado [Der Goldene Drache], de Roland Schimmelpfennig (nascido em 1967). Embora seja o mais encenado entre os dramaturgos contemporâneos de língua alemã (BERTON, 2010, p. 146), sua obra ainda é pouco conhecida no Brasil. ${ }^{1}$ Antes de mais nada, convém então apresentar o argumento da peça: o ponto central é um imigrante chinês recém-chegado à Alemanha e que trabalha, com quatro outros imigrantes orientais, na cozinha do restaurante de comida chinesa, tailandesa e vietnamita O Dragão Dourado. Ele procura pelo paradeiro de sua irmã, também imigrante no país, mas, por ora, uma dor de dente o impede de fazer o que quer que seja. Já que ele não tem nem dinheiro nem documentos, procurar ajuda médica está fora de questão. Como o restaurante fica no térreo de um prédio, a peça trata de subir as escadas para acompanhar as ações dos moradores. Então vemos também (a) um idoso que inveja a juventude de sua neta; (b) um casal prestes a romper o namoro; (c) um casal prestes a ter um bebê; (d) duas aeromoças, exaustas após um voo vindo do Chile, jantando no Dragão Dourado antes de subirem para casa; (e) o comerciante Hans lucrando menos com seu armazém do que com a exploração sexual de uma jovem chinesa (implicita mente a irmã do rapaz do restaurante) escondida em seu apartamento, embora essa
1. Até onde pudemos pesquisar, este é o primeiro trabalho crítico em português sobre a peça. Isso provavelmente se deve ao fato de a tradução brasileira, embor existente, ainda não ter sido publicada em livro ou veículo solicitar acso pácin acesso ao texto na Dramatik, do instituto Geutsche Drama 
2. [T]o rescue the "literature" half of the World Literature configuration from the de-aesthecizing jaws of globalization. As traduções são nossas, salvo menção contrária nas referências bibliográficas. narrativa seja a princípio apresentada como (f) uma reescrita da fábula da formiga e da cigarra.

Essas sete camadas bastariam para confundir até os leitores mais atentos. Mesmo assim, os temas principais da peça deixam-se identificar com clareza: a distribuição injusta dos benefícios da globalização, a dificuldade europeia em lidar com o outro, as identidades híbridas construídas nos entre-luga res da migração. Quanto a estas últimas, Bhabha (2003, p. 33) aventa a hipótese de hoje serem justamente as histórias de migrantes, colonizados e refugiados (todas ela condições de fronteira) o terreno da Weltliteratur de Goethe. De fato, Bhabha (2003, p. 32) se volta ao conceito goethiano em busca de "um método comparativo que fala ria à condição 'estranha' do mundo moderno”. E se, novamente de acordo com Bhabha (2003, p. 20), esses entre-lugares nos quais habita a Weltliteratur dão terreno à construção de novas identidades, interessa-nos aqui rastrear como a peça de Schimmelpfennig articula as relações entre capitalismo global, identidade e movimentos migratórios.

Comentando uma coletânea de ensaios editada em 2004 por Christopher Prendergast, Debating World Literature, Emily Apter (2013, p. 1) menciona seu esforço de "resgatar das garras desestetizantes da globalização a parte literária da literatura mundial”. ${ }^{2}$ Ou seja, pode-se também pensar a globalização na literatura mundial mais através de seu lado propriamente estético - "literatura" - do que de seu lado cultural e sociológico - representado pelo adjetivo "mundial" na expressão de Goethe. Assim, propomos também uma leitura cerrada de certos trechos representativos da peça de Schimmelpfennig. Com isso, poderemos não só desemaranhar o labirinto narrativo das várias camadas do texto, mas também observar como as relações migra tórias, cosmopolitas e globalizadas se relaciona m com os recursos literários e teatrais presentes na obra. Os questionamentos levantados a partir do texto de Schimmelpfennig tratam-se, como formula Franco Moretti (2003, p. 15), "do problema usual e, no fundo, do único problema real da história literária: a sociedade, a retórica e sua interação". Vamos então a ele.

\section{UMA ANÁLISE DA PEÇA}

No livro Globalização e literatura (2009), Suman Gupta discorre sobre o estatuto das cidades globais como consequência de um processo de desnacionalização dessas cidades. Superando a noção de pertencimento a algum país, elas passam a ser vistas como espécie de microcosmo do mundo globalizado:

Grandes espaços urbanos da América do Norte e da Europa Ocidental são muitas vezes entendidos como sendo maiores que seus locais geopolíticos e culturais conhecidos. Nova York, Chicago, Londres, Paris, por exemplo, são frequentemente apresentadas como mais que cidades

$\begin{array}{llllll}\text { EM TESE } & \text { BELO HORIZONTE } & \text { v. } 26 & \text { N. } 2 & \text { MAI-AGo. } 2020 & \text { ALVES; ALMEIDA. } 0 \text { grande teatro do mundo [...] }\end{array}$

Teoria, Crítica Literária, outras Artes e Mídias 
3. Large North American and Western European urban spaces are often signified as being greater than their ostensible geopolitical and cultural locations. New York, instance, are often presented as more than American or British or French Cities. They are understood and presented in media, political, sociological and also literary narratives as microcosms of the world at large, as 'world cities' or 'global cities'. There are several ways in which such a super-signification of these locations seems plausible [.... But perhaps most importantly these are cities that are simply enormously cosmopolitan - these are nodes of immigration and grobal movement, so that they diverse populations coexisting and cohabiting. a merica nas, inglesas ou fra ncesas. Elas são entendidas e apresentadas pelas narrativas midiáticas, políticas, socioló gicas e ta mbém literá rias como microcosmos do mundo em geral, como 'cidades mundiais' ou 'cidades globais'. Existem vários modos pelos quais uma super-significação dessas localidades parece possível [...]. Mas talvez o mais importante: são cidades enormemente cosmopolitas - são nódulos de imigração e movimento global, de modo que apresentam um mosaico extraordinário de populações diversas coexistindo e coabitando. ${ }^{3}$ (GUPTA, 2009, p. 38-9)

Pensar a cidade global enquanto esse microcosmo traz implicações para a configuração do próprio edifício no qua o restaurante O Dragão Dourado está situado. Através da metonímia, pode-se interpretar o edifício como um microcosmo da própria cidade, em que as populações diversas coexistem e coabitam, não de forma horizontal - como um mosaico -, mas vertical, hierárquica - pela sobreposição dos sujeitos, e de suas histórias, através dos andares. $\mathrm{O}$ restaurante ocupa a camada mais baixa, o térreo, que sustenta as outras seis camadas, situadas acima. Dentro dessa disposição, uma vez que o térreo ta mbém é um espaço de trânsito e circulação, os imigrantes ocupa m o lugar menos visível - a cozinha.

Da cozinha, o contato desses imigrantes com o mundo reduz-se à experiência dos pratos, da comida típica. Ao longo de toda a peça, há várias e minuciosas descrições dos pratos, mas nunca ficamos sabendo o nome de quem os prepara: "Número 74: À moda de Bangkok: pato com cogumelos frescos, páprica, broto de bambu, cebola, capim limão e curry vermelho com molho de coco. Picante. O pequeno chinês grita e grita, e não está acostumado com aguardente" (SCHIMMELPFENNIG, 2011, p. 13). Aqui, a falta de nome dos imigrantes; ali, o excesso de nome de descrição dos pratos: a estrutura capitalista não está interessada nas identidades ou nas histórias de vida desses imigrantes, mas no que eles podem oferecer enquanto valor comercial - nesse mercado, ta mbém se compra a cultura, a ideia que se faz de uma cultura, através da tipificação dos pratos. A coexistência e a coabitação tornam-se, ta mbém, uma forma de clausura e soterramento.

Já vimos que, segundo Bhabha (2003, p. 20), os entre-lugares presentes no mundo globalizado "fornecem o terreno para a elaboração de estra tégias de subjetivação - singular ou coletiva - que dão início a novos signos de identidade e postos inovadores de colaboração e contestação, no ato de definir a própria sociedade". Como apareceriam essas novas estratégias de subjetivação no contexto da peça de Schimmelpfennig? Há, segundo Jesús Martín-Barbero (2003, p. 72), um processo expansivo de fragmentação que ocupa todos aspectos da sociedade e não é oposto à globalização (com seu projeto de conectar as diversas partes

EM TESE BELO HORIZONTE $\quad$ v. $26 \quad$ N. $2 \quad$ MAIO-A60. $2020 \quad$ ALVES; ALMEIDA. 0 grande teatro do mundo [...] $]$ P. 266-282

Teoria, Crítica Literária, outras Artes e Mídias 
do mundo), mas complementar a ela. Se essa fragmentação é generalizada, pode-se esperar que esses sujeitos sejam tão fragmentados quanto a cultura dos locais que habitam. Bhabha observa que

o afasta mento de singularidades de 'classe' ou 'gênero' como categorias conceituais e orga nizacionais básicas resultou em uma consciência das posições do sujeito - de raça gênero, geração, local institucional, localidade geopolítica, orientação sexual - que habitam qualquer pretensão à identidade no mundo moderno. (BHABHA, 2003, p. 19-20)

Na peça de Schimmelpfennig, pode-se ver um jogo com essa fragmentação da identidade no mundo contemporâneo. Observe-se, por exemplo, a didascália indicando os atores e seus respectivos personagens:

\section{UM JOVEM HOMEM}

(O avô, um oriental, a garçonete, a cigarra)

\section{UMA MULHER DE MAIS DE SESSENTA}

(A neta, uma oriental, a formiga, um comerciante)

UMA JOVEM MULHER

(O homem de camisa listrada, um oriental com dor de

dente, o Barbiefucker)

\section{UM HOMEM DE MAIS DE SESSENTA}

(Um jovem homem, um oriental, a segunda aeromoça)

\section{UM HOMEM}

(A mulher de vestido, um oriental, a primeira aeromoça)

\section{(SCHIMMELPFENNIG, 2011, p. 2)}

Schimmelpfennig brinca com a inversão entre a identidade visual dos atores e os papéis que eles representam: a jovem mulher interpreta, entre outros, o homem de camisa listrada; o homem de mais de sessenta, uma aeromoça. $\mathrm{O}$ jovem homem é o avô; a mulher de mais de sessenta, a neta. A segunda cena joga com esse contraste entre o avô jovem e a neta idosa:

O JOVEM HOMEM. Se eu pudesse fazer um pedido.

Pausa.

Você -

Pausa curta.

Tão novinha. 
Pausa curta.

Você está tão linda.

A MULHER DE MAIS DE SESSENTA. Acha mesmo? Acha mesmo, avô?

Pausa.

Quando eu for assim, da sua idade - como

[é que eu vou ser?-

O JOVEM HOMEM. Isso eu não vou estar aqui para ver.

Não vou estar mais aqui para ver.

Eu rio.

Ele ri, ou sorri.

(SCHIMMELPFENNIG, 2011, p. 5)

Se eu pudesse fazer um pedido - por ora, não ficamos sabendo qual seria o pedido do avô, porém, mais à frente, a cena vinte e cinco deixa implícito que é a juventude que ele deseja, mais especificamente, o vigor sexual; e é na cena que joga com contrastes entre juventude e velhice que Schimmelpfennig começa a insinuar isso. Se eu pudesse fazer um pedido - o mote reaparece quase no fim da peça, no monólogo crucial que ocupa toda a cena quarenta e três. Nessa cena, reapa rece também o jogo com as identidades invertidas. ${ }^{4} \mathrm{~A}$ jovem aeromoça, interpretada pelo homem de mais de sessenta, está ao lado do Barbiefucker ${ }^{5}$ seu namorado interpretado pela jovem mulher, e imagina como seria poder inverter essas identidades cenicamente já trocadas:

\section{Se eu pudesse fazer um pedido.}

Se eu não fosse mais aeromoça nem namorada do Barbiefucker. E se o Barbiefucker não fosse mais o Barbiefucker. Se a gente pudesse trocar, aí eu seria o piloto que se manteve atraente, que já voou para além das fronteiras de cada um dos países deste planeta e ele, ele seria a aeromoça bonita, que leva a vida assim, de modo provisório, servindo comida em uma cápsula barulhenta a 33000 pés acima do mar.

Imagino como seria -

(SCHIMMELPFENNIG, 2011, p. 37)
4. Reaparece também o motivo da velhice: "Eu sou jovem demais para ele. Eu me pergunto o que ele sente, quando toca em meu roço ta joven. Quando eu r vo hice. Ele é be, percebo é um homem atraente. Mas eu percebo a velhice na pelo del" (SCHIMMELPFENNIG, 2011, p. 37). A insistência em um tema da vida privada pode parecer estranha em uma peça sobre os problemas da globalização, mas as duas esferas não deixam de estar relacionadas. Conforme escreve Martín-Barbero (2003, p. 58), "a globalização pesa tanto ou mais no plano dos imaginários cotidianos das pessoas

do que sobre os processos

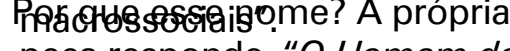
peça responde. "O Homem de mais de sessenta: Quando Eva e o namorado se encontraram, ele disse para ela, você parece uma boneca Barbie $-A$ jovem mulher: Você parece uma mais de sessenta: E quando eles ficaram juntos, ela disse para ele: agora você é o Barbiefucker. Agora vocế é Barbiefucker"

(SCHIMMELPFENNIG, 2011, p. 33). 
Mas quando chamamos o monólogo de "crucial" não foi exatamente devido a esse jogo de identidades. Vocês repararam como o cosmopolitismo aparece nele? Temos o modo de vida provisório, a aeromoça a trinta e três mil pés acima do mar, o piloto que já cruzou todas as fronteiras do globo. Trata-se, porém, de algo diferente daquele cosmopolitismo dos imigra ntes quase forçados na cozinha do Dragão Dourado. Bhabha (2011) distingue duas espécies de cosmopolitismo: o global e o vernacular. Por cosmopolitismo global, Bhabha entende "um cosmopolitismo de rela tiva prosperidade e privilégio fundamentado em ideias de progresso que são cúmplices de formas neoliberais de governança e de forças de concorrência de livre mercado" e que pode ter "fé nos poderes praticamente sem fronteiras da inovação tecnológica e das comunicações globais" (BHABHA, 2011, p. 177-8). O estudioso nota ainda que os países participantes "desse multinacionalismo multicultura afirmam seu compromisso com a 'diversidade', em casa e no exterior, enquanto a demografia da diversidade consiste em grande parte de migrantes econômicos cultos [...], em vez de refugiados, exilados políticos ou pobres" (BHABHA 2011, p. 178), dando pouca atenção à desigualdade e à pobreza geradas no processo.

O cosmopolitismo vernacular, por sua vez, é aquele que surge "do mundo de pensões de imigrantes e de habitações de minorias nacionais ou diaspóricas" e que "mede o progresso global a partir de uma perspectiva minoritária" (BHABHA, 2011, p. 180-181). É o cosmopolitismo daqueles "refugiados, exilados políticos e pobres" rejeitados pelo cosmopolitismo global. Ele está explícito na décima terceira cena de O Dragão Dourado, quando o cozinheiro vietnamita diz:

Tudo estreito, uns poucos metros quadrados de azulejo, talvez uns quatro ou cinco, o fogão a gás e a fritadeira, as bancadas, as geladeiras, ali do lado um pequeno espaço para os mantimentos, um relógio e uma parede, e um calendário com fotos do Vietnam, do atacadista vietna mita, eu gostaria muito de estar no Vietnam, a região costeira deve ser linda. (SCHIMMELPFENNIG, 2011, p. 14, grifos nossos)

Ao comentário sobre as condições impróprias de trabalho que com frequência acompanham o cosmopolitismo vernacular (tudo estreito, uns poucos metros quadrados de azulejo), segue-se - com o calendário na parede servindo para fazer a transição - um comentário sobre a vontade de voltar ao Vietnam e sobre como a região costeira deve ser linda. Esse detalhe sugere que o próprio vietnamita não conhece todo o Vietnam, questionando assim visões essencialistas acerca das minorias globais. Para os cosmopolitas vernaculares, escreve Bhabha (2011, p. 181), "suas reivindicações à liberdade e à igualdade são marcadas por 'um direito à diferença na igualdade', em vez de uma diversidade fundada em uma 'economia 
dual". Entretanto, ele prossegue, "tal direito à diferença [...] não exige a restauração de uma identidade cultural ou grupal original [ou essencialista]" (BHABHA, 2011, p. 181).

Um cosmopolitismo vernacular, portanto. Temos uma imagem ainda mais brutal dele na camada da peça que começa como uma revisão da fábula da cigarra e da formiga. Schimmelpfennig revisita, é claro, um material que remonta a Esopo. Aqui está o texto do autor grego:

Era inverno e as formigas estavam secando o trigo encharcado, quando uma cigarra faminta lhes pediu alimento. As formigas lhe disseram: "Por que, no verão, você ta mbém não recolheu alimento?”. E ela: "Mas eu não fiquei à toa! Ao contrário, eu cantava canções melodiosas! Elas tornaram, a rir: "Mas se você flauteava no verão, dance no inverno!" (ESOPO, ed. Chambry 336, ed. Perry 373)

Desde o "Pierre Menard", de Jorge Luis Borges, sabemos que, havendo uma mudança de contexto, é possível até repetir linha por linha de um texto literário e ainda assim gerar sentidos muito diferentes. Se Esopo ficava contente em extrair da fábula uma moral como "não devemos descuidar de nenhuma tarefa, para não padecer aflições nem correr riscos" (ESOPO, ed. Chambry 336, ed. Perry 373), em tempos de neoliberalismo, ela nos lembra do discurso meritocrático e do conhecido desdém do capitalismo pelas atividades (criativas, no caso) que não lhe servem diretamente. São conotações desse tipo que a peça de Schimmelpfennig associa à fábula:

A formiga dá conselhos à ciga rra faminta. Faxina. Você pode fazer faxina. Se quiser levar alguma coisa vai ter que fazer por merecer.

\section{Que tal faxina?}

\section{É. Faça faxina.}

Ou então - me ocorreu uma ideia -

\section{(SCHIMMELPFENNIG, 2011, p. 16)}

A ideia que ocorre à cigarra é explicitada na cena dezenove:

A formiga agencia a cigarra para as outras formigas. As formigas ficam muito a fim da cigarra. Acham a cigarra safadinha, acham a cigarra atrevida, curtem o sotaque dela [...]. Fodem com ela, uma depois da outra. Em troca disso, a cigarra recebe algo para comer. Restos de mosca morta. Mas às vezes a cigarra também não recebe nada. Nessas horas, as formigas dizem que a cigarra tem que se dar por satisfeita, já que tem um teto para morar. Dizem que a cigarra tem que se dar por satisfeita, já que as formigas não mandam ela embora. De volta. De volta para a neve. 


\section{(SCHIMMELPFENNIG, 2011, p. 17)}

À medida que a peça avança, percebemos que a narrativa da cigarra não é um interlúdio nem uma camada autônoma da ação. Cena trinta e cinco: o comerciante Hans convida o homem prestes a se divorciar para beber em seu apartamento. Entrando na casa de Hans, o homem exclama que "o apartamento do comerciante não é um apartamento coisa nenhuma. É a ntes um depósito, abarrotado até o teto de mantimentos. Arroz, macarrão, leite longa vida, sal, açúcar para todo lado, abarrotado por toda parte" (SCHIMMELPFENNIG, 2011, p. 32). Depois dessa fala, os leitores mais minuciosos terão percebido a semelhança com a formiga estocando mantimentos. Mas mesmo os mais displicentes percebem a sobreposição das duas camadas depois do que se passa na casa de Hans durante a cena quarenta e cinco:

O JOVEM HOMEM. A cigarra pensou que a formiga tivesse adormecido, mesmo com toda a barulhada, por ter bebido demais, e assim ela saiu do quarto [...].

A JOVEM MULHER. De repente, há uma jovem oriental no cômodo.

Pausa.
De repente há uma jovem oriental no cômodo.

Eu digo:

Ei, você saiu de onde?

(SCHIMMELPFENNIG, 2011, p. 38)

A cigarra explorada em troca de restos de mosca morta correspondia à jovem imigrante oriental; as formigas, com casas abarrotadas de mantimentos, aos europeus. $\mathrm{Na}$ interpretação de Sophia Aichinger (2011, p. 54), "quando olhamos mais de perto, a parábola de Schimmelpfennig reflete tanto a divisão injusta de recursos entre os países emergentes e os industrializados quanto a exploração de países de terceiro mundo para fins de consumo"6. A lógica da globalização põe em contato, unifica os dois pontos do globo, mas, conforme Martín-Barbero (2003, p. 58), "a única dimensão realmente mundial até agora é o mercado, que mais que unir, busca unificar (Milton Santos). E atualmente o que está unificado em nível mundial não é uma vontade de liberdade, mas sim de domínio". Na peça, temos: "E então ele tra tou a cigarra não como uma cigarra, mas como uma coisa, por algo assim se pode pagar então tanto faz se ela quebrar" (SCHIMMELPFENNIG, 2011, p. 30, grifo nosso).

Questionado sobre uma outra obra, sua Trilogie der Tiere [Trilogia dos Animais], Schimmelpfennig diz que "a forma
6. Bei genauerer Betrachtung spiegelt Schimmelpfennigs Parabel von der Grille und der Ameise die ungerechte Ressourcenverteilung zwischen Entwicklungslandern und westlichen Industriestaaten und die Konsum orientierte Ausbeutung der Dritte Welt Länder. 
[...] desempenha para mim apenas um papel secundário. $\mathrm{O}$ tema encontra a forma. Ele não precisa seguir um direcionamento externo. A forma segue o conteúdo. Não o contrário. Qualquer outra coisa ou não faria sentido ou seria afetada, falsa"7 (SCHIMMELPFENNIG apud LAUDAHN 2012, p. 20). Poderíamos questionar a dicotomia entre forma e conteúdo empregada aqui, mas o ponto principal não é esse. O que essa fala tem de mais relevante é aquilo que deixa implícito. Se a forma segue o tema, e o tema da peça são preocupações políticas e sociais da Europa hoje (a globalização, o fluxo de migrantes), logo essas preocupações influenciam a própria estrutura da escrita dramática. "Se está chovendo enquanto caminho por uma rua da antiga Berlim Oriental e penso este início”, o poeta Ricardo Domeneck (2007, p. 117, grifo nosso) se pergunta em Composição como contexto, "quanto o caminho, a velocidade dos passos e o vento frio no rosto influenciam $o$ ritmo desta oração?”. Quer dizer, o contexto histórico de produção afeta o trabalho com a materialidade da linguagem, afeta o jogo formal da obra literá ria ("o ritmo desta oração").

Em outra entrevista, o dra maturgo alemão afirma ter achado especialmente difícil trabalhar com o tema da imigração ilegal, que perpassa O Dragão Dourado: "como é possível se fazer justiça a esse tema enquanto dramaturgo alemão? É uma tarefa difícil, que para mim não se resolve com os recursos convencionais do teatro"s (SCHIMMELPFENNIG, 2010, $\mathrm{s} / \mathrm{p}$, grifos nossos). Isto é, para o autor, o contexto de sua enunciação e a própria natureza do tema também seriam responsáveis pelos procedimentos pouco ortodoxos da peça.

Mas quais procedimentos são esses, exatamente? O mais explícito é o uso dos efeitos de estranhamento [Verfremdungseffekte] sistematizados por Bertolt Brecht para seu tea tro épico. Como observa Aichinger (2011, p. 52), "os efeitos de estranhamento de Schimmelpfennig provocam um novo olhar sobre sistemas de poder aparentemente imutáveis e também uma discussão crítica sobre essas estruturas hierá rquicas" ${ }^{\prime \prime}$. Entre os artifícios ligados a esse efeito de estranhamento, Brecht recomendava que atores representassem em terceira pessoa, transpusessem a ação para o passado e dissessem as didascálias em voz alta (BALME, 2008, p. 24). Com isso, seria alcançado entre o ator e o papel um distanciamento propício não à expressão de experiências pessoais, mas de problemas políticos e sociais mais abrangentes. Pode-se argumentar que o teatro de Schimmelpfennig não é tão explicitamente engajado qua nto o de Brecht, mas os efeitos de estranhamento continua m presentes. Aqui está outro exemplo:

\section{A JOVEM MULHER. O homem de camisa listrada:}

Talvez uns trinta anos, já bebeu demais. Sentado, sozinho, em seu apartamento, à mesa da cozinha. Olha para a mesa,
7. Die Form [...] spielt für mich nicht mehr als eine untergeordnete Rolle. Der Stoff findet die Form. Rolle. Der Stoff findet die For
Er braucht keine äußerliche Zuordnung. Die Form folgt dem Zuordnung. Die Form folgt dem
Inhalt. Nicht andersherum. Alles Inhalt. Nicht andersherum. Alles falsch.

9. Schimmelpfennigs Verfremdungseffekte provozieren eine neue Sichtweise auf scheinba unverrückbare gesel/schaftliche Machtsysteme und eine kritische hierarchischen Strukturen.

$\begin{array}{llllll}\text { EM TESE } & \text { BELO HORIZONTE } & \text { v. } 26 & \text { N. } 2 & \text { MAI-AG0. } 2020 & \text { ALVES; ALMEIDA. } 0 \text { grande teatro do mundo }[\ldots]\end{array}$

Teoria, Crítica Literária, outras Artes e Mídias 
olha para a geladeira. A namorada o deixou, ou pensa em deixá--lo e ele agora está na esperança de que ela volte.

Ele diz: Eu queria que ela nunca tivesse se encontrado com ele.

Se ela nunca tivesse se encontrado com ele -

Um tanto rude. Meio desiludido.

Se ela nunca tivesse se encontrado com ele -

Um movimento súbito. Nisso eu derramo um pouco de cerveja nas calças.

Ela derrama um pouco de cerveja.

(SCHIMMELPFENNIG, 2011, p. 7)

É interessante que o termo "Verfremdungseffekt"[efeito de estranhamento] de Brecht seja derivado de fremd, adjetivo alemão para "estranho", mas ta mbém traduzível por "estrangeiro". O contato dos europeus com estrangeiros é um tema central em O Dragão Dourado, e Bhabha (2003, p. 30) nos fala sobre certo tipo de "estranhamento" inerente a um rito de iniciação extraterritorial e intercultural. Uma das sequências da peça em que isso se dá com mais ênfase começa com a extração do dente daquele oriental com dores na primeira cena. Extraído na cozinha do restaurante, o dente vai parar na sopa de uma das clientes, a aeromoça alemã voltando do trabalho:

A JOVEM MULHER. O dente voa e voa.

O JOVEM HOMEM. Voa e voa.

O HOMEM. E voa e voa através da cozinha minúscula d' O DRAGÃO DOURADO.

O JOVEM HOMEM. O dente arrancado voa e voa.

A MULHER DE MAIS DE SESSENTA. Voa e voa e vai pousar no wok.

(SCHIMMELPFENNIG, 2011, p. 20)

O que acontece então? A aeromoça encontra o dente, vai embora do restaurante (eu não fico aqui nem mais um minuto), mas apesar da repulsa leva o dente consigo na bolsa. Uma vez em casa, o que fazer com o dente? Ela, que, lembremos, é interpretada por um homem, não consegue se decidir:

O dente permanece sobre a mesa, diante da mulher loura.

A mulher coloca o dente na boca.

O Homem coloca o dente na boca. 
O dente tem gosto de sopa tailandesa e um pouco de gosto de sangue.

A língua dela passeia em volta do dente estranho.

A língua dele passeia em volta do dente estranho.

E então a aeromoça volta a colocar o dente sobre a mesa.

O que ela fará com o dente? Ela não pode simplesmente jogá-lo fora.

(SCHIMMELPFENNIG, 2011, p. 35)

Não pode simplesmente jogá-lo fora, mas é justamente isso que ela faz na última cena, lançando-o em um rio para “desaparecer na escuridão". Segundo Aichinger (2011, p. 55), a cena diz tanto sobre estruturas sociais de poder qua nto a sequência com a cigarra e a formiga. Ela nota que

também a fascinação aparentemente disparatada da aeromoça Inga pelo dente podre revela um problema social recalcado. Comendo o prato asiático, ela consome também o dente podre. Inga coloca em sua boca o dente repleto de cáries. Ela quer sentir a dor que derrubou esse dente. Ao invés de investigar por que o dente foi parar na sopa - e com isso procurar pelo problema no sistema social - ela, após o breve interesse, cospe o dente no rio como "um caroço de cereja". ${ }^{10}$ (AICHINGER, 2011, p. 56)
Em outra cena, Schimmelpfennig faz com que a imagem do dente boiando na sopa se toque com uma imagem a náloga, porém de maior escala: um bote na costa africana com pessoas tentando a travessar o mar em direção à Europa. O trecho é este:

A MULHER DE MAIS DE SESSENTA. O longo voo sobre o oceano, depois, nos monitores, dá para ver como o avião rasteja, a 900 quilômetros por hora, pela costa oeste da África.

O HOMEM DE MAIS DE SESSENTA. Mas quando se olha para baixo, da janela, não dá para ver muita coisa.

O HOMEM. A aeronave lotada até o último acento. Chilenos, argentinos, bolivianos, com cara de índio.

O JOVEM HOMEM. A comida é servida, pode-se escolher entre um fricassê de frango ou uma massa.

O HOMEM. E à medida que voam sobre Angola, Gabão, Libéria e Serra Leoa, e agora chegam à altura de Gâmbia, Senegal e Mauritânia, Inga, uma das duas aeromoças, fala para Eva, a outra aeromoça, olha lá embaixo -
10. Auch die scheinbar absurde Faszination der Stewardess Inga für den faulen Zahn enthüllt einen verdrängten gesellschaftlichen Missstand. Sowie sie die asiatischen Speisen essen, wird auch der faule Zahn konsumiert. Inga steckt den schwer kariösen Zahn in ihren Mund. Sie möchte den Schmerz, den dieser Zahn ausgelost hat, nachempfinden. Statt die Ursachen für den faulen Zahn in der Suppe - und damit die Missstande im System - zu suchen, spukt sie den Zahn nach kurzem Interesse , wie einen Kirschkern" in de

Teoria, Crítica Literária, outras Artes e Mídias 


\section{O HOMEM. Lá! Não é um bote?}

O HOMEM DE MAIS DE SESSENTA. Um bote? Como você ia ver isso daqui?

O HOMEM. É! É um bote! Um bote cheio de gente, não está vendo?

O HOMEM DE MAIS DE SESSENTA. A dez quilômetros de altura? -

\section{(SCHIMMELPFENNIG, 2011, p. 23)}

Há uma aparente contradição quando se diz que a aeronave "rasteja" a novecentos quilômetros por hora. $\mathrm{O}$ oximoro, no entanto, diz muito sobre as relações com o espaço introduzidas pelas tecnologias de transporte que viabilizam a globalização. Embora a velocidade seja espantosa, a aeronave ainda assim rasteja porque o tamanho do trajeto consegue ser ainda mais espantoso. Ao mesmo tempo que encurta distâncias, a globalização as aumenta, pois viabiliza a própria possibilidade de se cruzar esses grandes percursos (compare-se com nem pensar em sair da própria vila e logo se vê o que temos em mente). Aliás, não é a única vez que termos relativos à aviação aparecem no texto. Lembrem-se da aeromoça vivendo provisoriamente a trinta e três mil pés acima do mar, do piloto que cruzou o mundo, ou da insistência no verbo "voar" na cena em que o dente arrancado pousa ${ }^{11}$ na sopa da aeromoça.

Isso nada tem de fortuito, é claro. Essas escolhas lexicais reforçam na própria linguagem os temas relacionados ao conta to com o outro, à globalização e ao cosmopolitismo (global ou vernacular) presentes na ação da peça. A presença desses temas parece especialmente saturada nas cenas finais. $\mathrm{O}$ chinês não resiste muito tempo à extração de dente, e, após algumas cenas sangrando sem parar, termina morto na cozinha do restaurante. Mas logo após a constatação da morte, a primeira fala que se segue é o aviso de um prato pronto para entrega: "Número 5: Bo Xao Xa Ot, carne bovina assada, com acelga, páprica, cogumelos vietna mitas, brotos de ba mbu, cebola, alho, capim, limão" (SCHIMMELPFENNIG, 2011, p. 36). É como se dissessem: temos um corpo aqui e isso é péssimo, mas, afinal, a máquina de produção capitalista não pode parar. Certamente não por ele. Mas o que fazer com esse corpo?

A JOVEM MULHER. Eles enrolam o pequeno chinês em um tapete, que tiraram da parede do salão da frente d'O Dragão Dourado, já que há pouco não havia ninguém no restaurante.

É o tapete com o dragão dourado, que ele sempre quis observar com mais cuidado, pois não havia um tapete daqueles na casa em que ele morava. E agora é tarde demais.
11. No original, esse "pousar" é "landen", verbo relacionado a "Land", isto é, terra, território, país - o que daria ainda mais implicaçôes à cena se a lermos pensando na globalização e no cosmopolitismo.
EM TESE
BELO HORIZONTE
v. 26
N. 2
MAIO-AGO. 2020
ALVES; ALMEIDA. 0 grande teatro do mundo [...]
P. 266-282

Teoria, Crítica Literária, outras Artes e Mídias 


\section{(SCHIMMELPFENNIG, 2011, p. 38, grifos nosso)}

Aqui a relação entre capital e cosmopolitismo vernacular fica mais explícita do que nunca na peça. Ele sempre quis ver melhor o tapete com o dragão dourado, sua colega diz, porque na casa dele não havia um desses. O dourado carrega toda uma conotação financeira (a cor do ouro) e o dragão é um símbolo de prosperidade na China. Ou seja, ele viajou desde a China para se aproximar de uma riqueza inexistente em seu país. Mas agora é tarde, a globalização nunca nutriu grandes simpatias por esse tipo de cosmopolitismo. Uma vez envolto o corpo, os demais vão até uma ponte e o despacham no rio. O que se segue talvez seja a passagem mais pungente da peça, com uma série de topônimos evocando imagens concretas de uma geografia global enqua nto o morto se dirige a seus parentes na China:

Eu caio na ponte, na água, meu corpo afunda no rio gélido, a água atravessa o buraco deixado pelo dente, para dentro de mim, e eu nado para casa.

O rio me lança no Mar do Norte, uma corrente me conduz até a Escandinávia, passando pela Noruega, pela Finlândia e pela Rússia, rumo ao mar gelado do ártico, e quando o mar congela, sigo por baixo do gelo, talvez um peixe me arraste, ou uma baleia.
Cruzo toda Rússia e toda Sibéria pelo Mar Ártico, é uma viagem longa.

Atravesso o Estreito de Bering e o Mar de Bering.

E então vem a Península de Kamchatka -

não falta muito, logo estarei em casa.

Atravesso o longínquo Japão, ao nascer do dia, e perto da noite do mesmo dia, finalmente: a China.

Já estou lá, já estou quase em casa. Só mais 3000 quilômetros Rio Amarelo acima, o Huang Ho, contra a correnteza, contra a correnteza, Huang Ho acima, atravessando três províncias, primeiro a leste, depois a norte e aí estou em casa.

Mas como eu pareço? Por quanto tempo estive de viagem? Semanas? Meses?

Ou anos? Foi uma viagem longa. Foi uma viagem muito longa. Podem ter se passado anos de viagem.

Como eu pareço? Sem mais nenhuma carne nos ossos, lavados por água salgada e por água doce. Algumas algas. Talvez não seja uma bela visão.

Feliz por estar de volta em casa. 


\section{Com fome.}

Olá, venerável tio, sinto muito, todo aquele dinheiro, todas aquelas cédulas que vocês juntaram e que nunca mais verão.

Não, não verão nunca mais, sinto muito.

Mas a viagem de volta eu fiz de graça, de graça e absolutamente sozinho.

Minha irmã -

Não, minha irmã eu não encontrei nunca, me desculpe, não foi nada fácil, ela não voltou já faz um tempo?

Eu sempre tive a sensação de que ela estava perto. Talvez ela esteja bem.

(SCHIMMELPFENNIG, 2011, p. 41)

\section{CONSIDERAÇÕES FINAIS}

A última cena da peça nos mostra a aeromoça cuspindo o dente do chinês no rio embaixo da mesma ponte de onde lançaram seu corpo. A ponte é uma imagem apropriada para o fim de uma obra sobre as ondas migratórias na Europa, pois ela mesma já é um símbolo de travessia, de conta to entre dois locais. Martin Heidegger escreve que "sempre, e sempre de modo diferente, a ponte acompanha os caminhos morosos ou apressados dos homens para lá e para cá, de modo que eles possam alcançar outras margens... A ponte reúne enqua nto passagem que atravessa" (HEIDEGGER apud BHABHA, 2003, p. 24, grifo no original). Mas essa reunião é marcada pelo hábito de, como escreve Martín-Barbero (2003, p. 72), "simplificar o outro, ou melhor, descomplexizá-lo, torná-lo assimilável sem necessidade de decifrá-lo”.

"Número 83: Pad Thai Gai: talharim frito de arroz,com ovo, legumes, frango e molho apimentado de amendoim, médio picante" - aos imigrantes d'O Dragão Dourado, cada prato servido retoma a certeza de ser estrangeiro, invisível, nesse grande teatro de não pertencimento. É inegável que um cosmopolitismo do tipo vernacular é uma urgência primordialmente daqueles que não têm a liberdade de cosmopolitismo, mas apenas o precário, concebendo a ntes um projeto cosmopolita de sobrevivência, ao qual, muitas vezes, o corpo sucumbe - soterrado, submerso: "na minúscula cozinha do restaurante expresso de comida tailandesa, chinesa e vietnamita"; "no fundo do rio [onde] jaz um dente" (SCHIMMELPFENNIG, 2011, p. 3-43).

"Número 76: Phad Med Mamoang Nuah: carne bovina assada, com páprica, cebola, cenoura e castanha de caju em

EM TESE

BELO HORIZONTE

v. 26

N. 2

MAIO-AGO. 2020

ALVES; ALMEIDA. 0 grande teatro do mundo [...]

P. 266-282

Teoria, Crítica Literária, outras Artes e Mídias 
molho de coco e amendoim" - na peça de Schimmelpfennig, vemos como as ancoragens territoria is são relativizadas mas os princípios do mercado nem tanto. Bhabha (2011, p 178) sugere que a globalização deve começar em casa: "uma medida justa de progresso global exige que primeiro avaliemos como as nações globalizantes lidam com a 'diferença por dentro' - os problemas da diversidade e redistribuição em nível local e os direitos e representações de minorias em nível regional". Bhabha (2003, p. 33) sugere ta mbém, como vimos, a hipótese de as histórias transnacionais das minorias globais serem, hoje, o espaço da literatura mundial. Bem, a Weltliteratur, como articulada por Goethe, contrapõe-se às demarcações nacionais, e, por definição, não pode não ser, de alguma forma, cosmopolita. Mas de que forma? Se aceitarmos a hipótese de Bhabha, responderemos que, na contempora neidade, o cosmopolitismo da literatura mundial é o cosmopolitismo vernacular.

\section{REFERÊNCIAS}

AICHINGER, S. Die Bedeutung von Verlust im

Werk von Roland Schimmelpfennig. 2011. $90 \mathrm{f}$.

Monografia (Graduação em Teatro) - Philologisch-

Kulturwissenschaftliche Fakultät, Universität Wien, 2011.

Disponível em: < othes.univie.ac.at/16586/>. Acesso em

29 ago. 2020.
APTER, E. Against World Literature. On the politics of untranslatability. Londres e Nova York: Verso, 2013.

BALME, C. B. The Cambridge introduction to Theatre

Studies. Cambridge: Cambridge University Press, 2008.

BERTON, P. R. Committed drama within postdramatic

theatre: a study of contemporary German language plays 2010. $203 \mathrm{f}$. Tese (Doutorado em Teatro) - Department of

Theatre and Dance, University of Colorado, 2010. Disponível em: <scholar.colorado.edu/downloads/bv73c0780>

Acesso em: 29 ago. 2020.

BHABHA, H. Olhando para trás, indo para frente:

observações sobre o cosmopolitismo vernacular. Prefácio à edição Routledge Classics. In: $\mathbf{O}$ bazar global e o clube dos cavalheiros ingleses. Textos seletos. Trad. Teresa Carneiro. Rio de Janeiro: Rocco, 2011, p. 172-191.

O local da cultura. 2 reimp. Trad. Myriam Ávila, Eliana Lourenço de Lima Reis e Gláucia Renate Gonçalves. Belo Horizonte: Editora UFMG, 2003.

BORGES, J. L. Pierre Menard, autor do Quixote. In: Ficções Trad. Davi Arrigucci Jr. São Paulo: Companhia das Letras, 2016, p. 34-45. 
DOMENECK, R. Composição como contexto. In: a cadela sem Logos. São Paulo: Cosac Naify, 2007, p. 114

\section{ECKERMANN, J. P. Conversações com Goethe nos últimos} anos de sua vida: 1823-1832. Trad. Mario Luiz Frungillo. São Paulo: Editora UNESP, 2017.

ESOPO. Fábulas completas. 3. reimp. Trad. Maria Celeste C. Dezotti. São Paulo: Cosac Naify, 2016.

GUPTA, S. Globalization and literature. Cambridge: Polity, 2009

\section{LAUDAHN, C. Zwischen Postdramatik und Dramatik.}

Roland Schimmelpfennigs Raumentwürfe. Tübingen: Narr, 2012

MARTÍN-BARBERO, J. Globalização comunicacional e transformação cultural. Trad. Eliana Aguilar. In: MORAES, D. (org.). Por uma outra comunicação. Rio de Janeiro: Record, 2003, p. 57-86.

MORETTI, F. Atlas do romance europeu. 1800-1900. Trad. Sandra Guardini Vasconcelos. São Paulo: Boitempo Editorial, 2003
SAID, E. Orientalismo. O Oriente como invenção do Ocidente. 7 reimp. Trad. Rosaura Eichenberg. São Paulo: Companhia das Letras, 2017

SCHIMMELPFENNIG, R. Der Goldene Drache. Frankfurt am Main: S. Fischer, 2008

„Eine aufregende Zeit, um für das Theater zu schreiben". 2010. Entrevista concedida a Franz Wille.

Disponível em: < der-theaterverlag.de/theater-heute/archiv/ artikel/das-stueck-des-jahres-der-goldene-drache-rolandschimmelpfennig/>. Acesso em: 12 dez. 2019.

O Dragão Dourado. Trad. Marcos Barbosa. 2011 Disponível em: <goethe.de/kue/the/nds/nds/bib/ptindex. htm >. Acesso em: 12 dez. 2019.

Recebido em: 07-12-2020 Aceito em: 17-01-2021 